
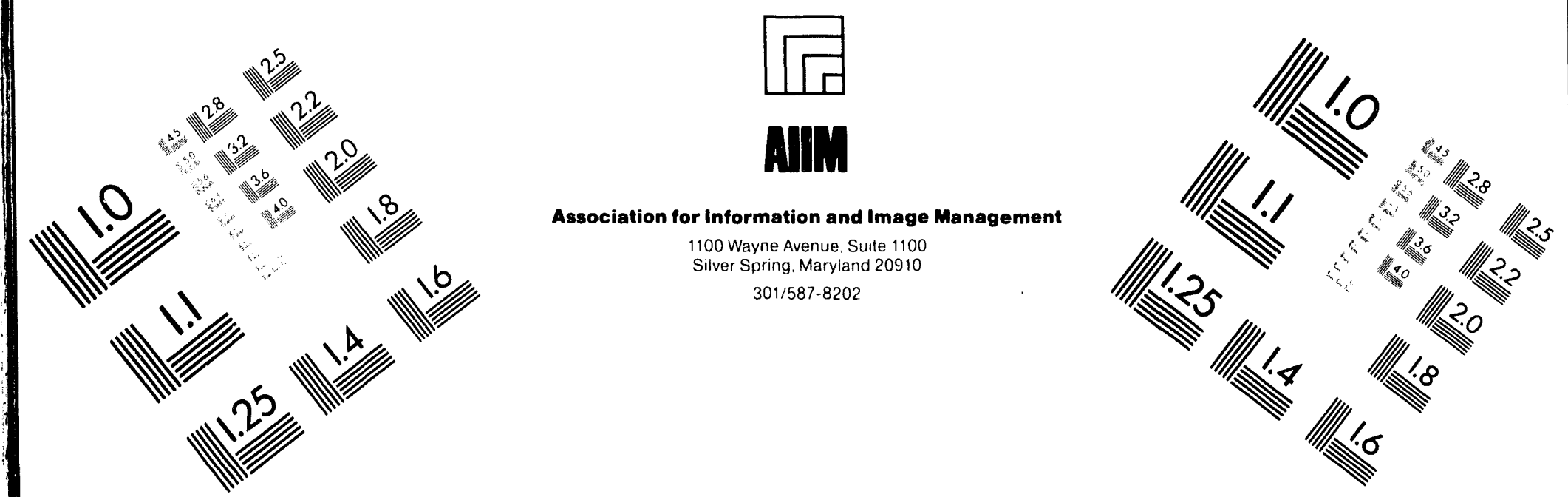

\title{
Centimeter
}

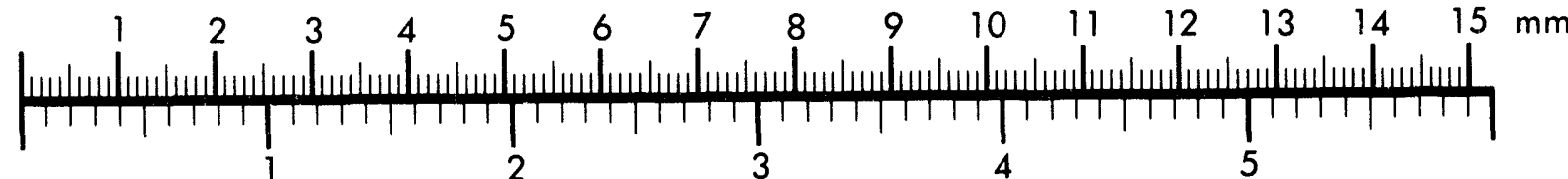

Inches
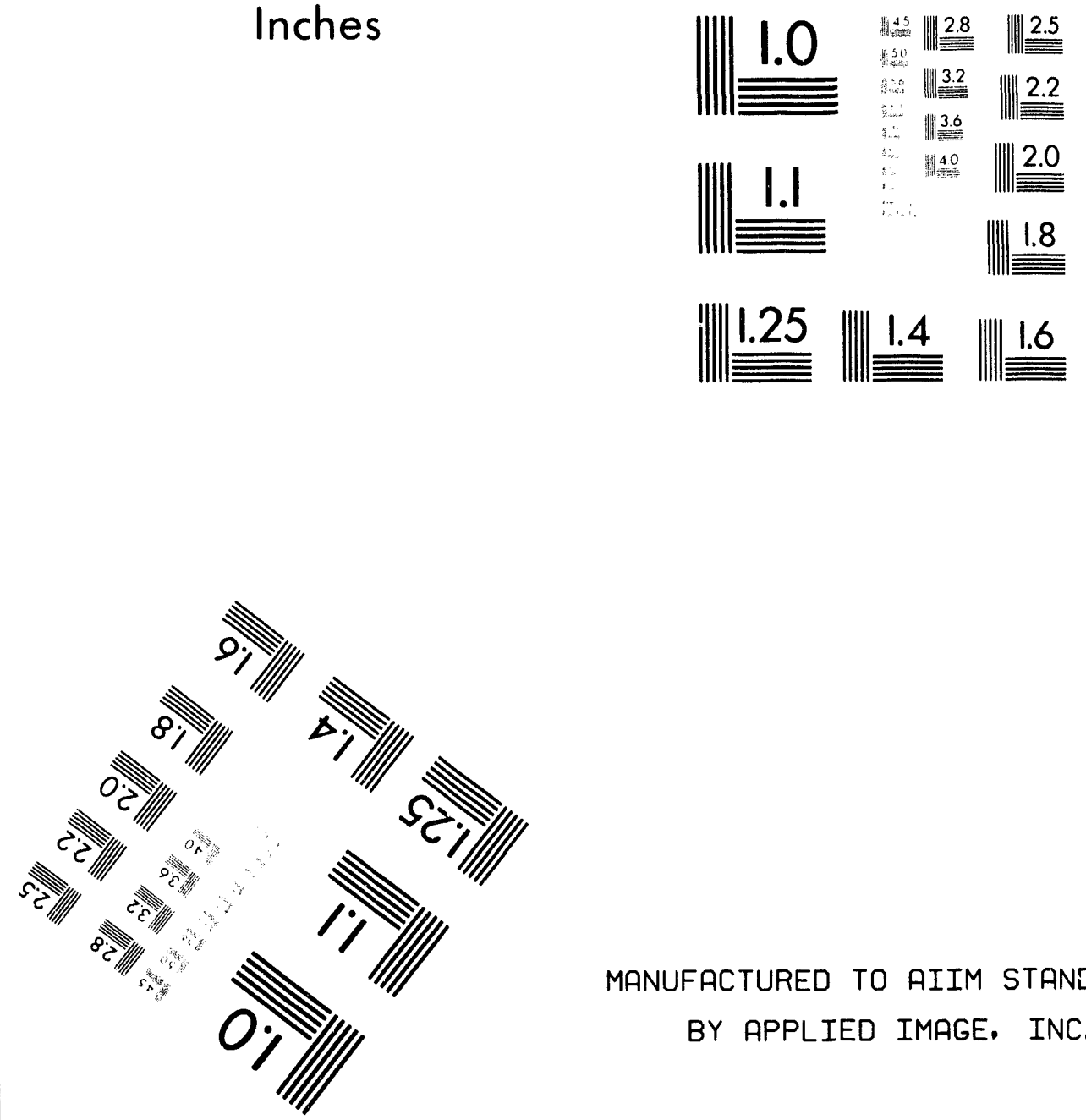

MANUFACTURED TO AIIM STANDARDS

BY APPLIED IMAGE. INC.

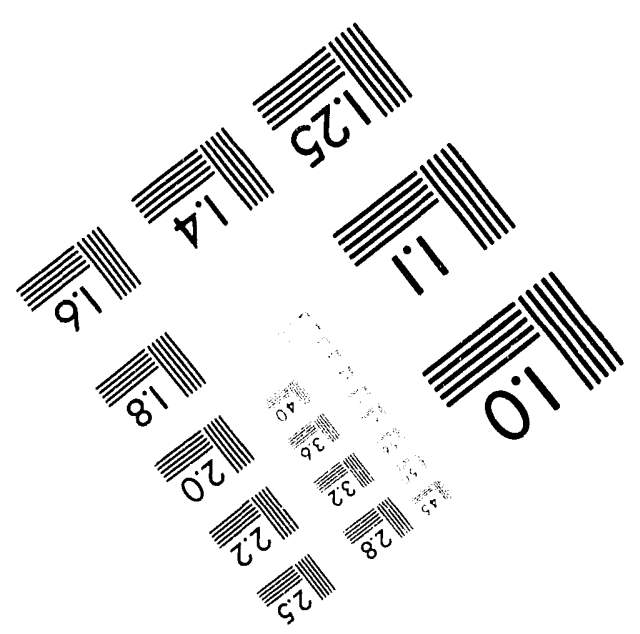



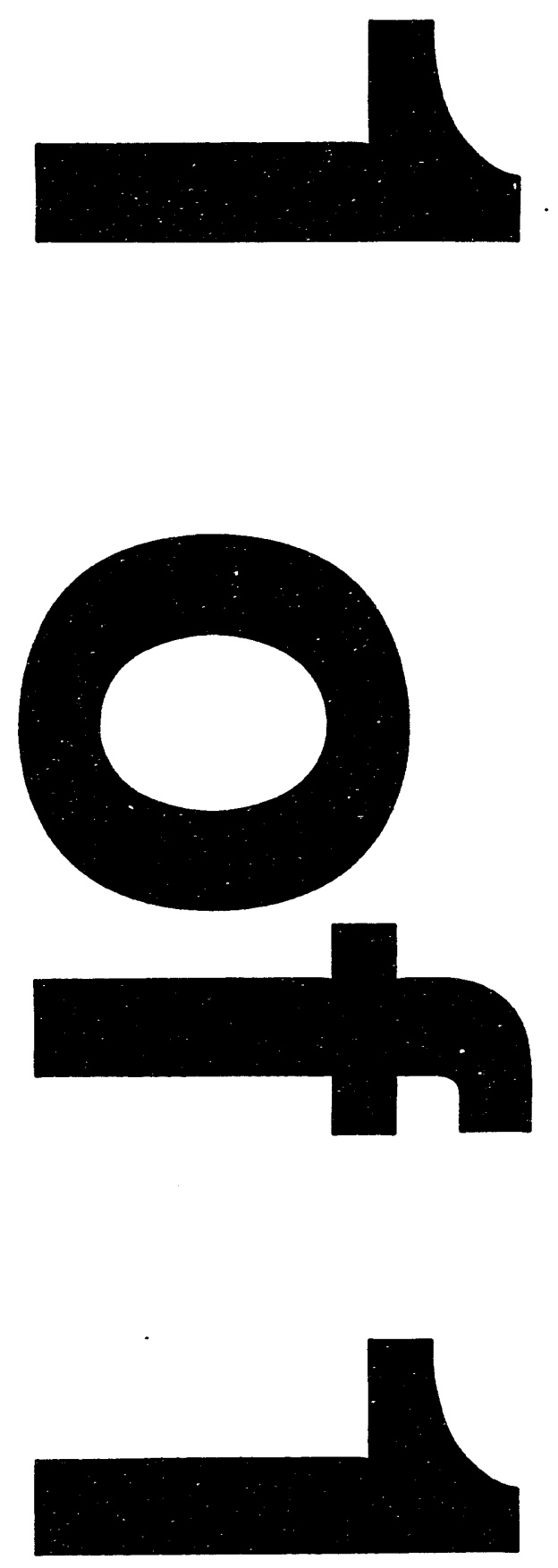


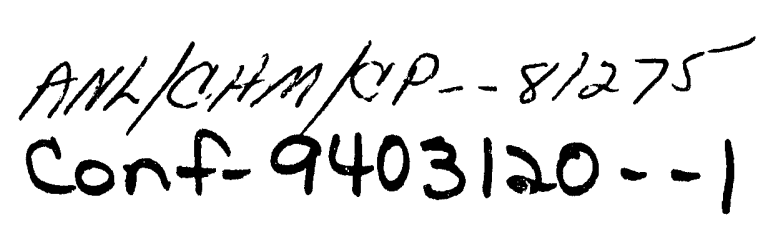

TIME-OF-FLIGHT PULSED ION BEAM SURFACE ANALYSIS

AS A MEANS OF IN SITU, REAL-TIME CHARACTERIZATION

OF THE GROWTH OF FERROELECTRIC AND CONDUCTIVE

OXIDE HETEROSTRUCTURES

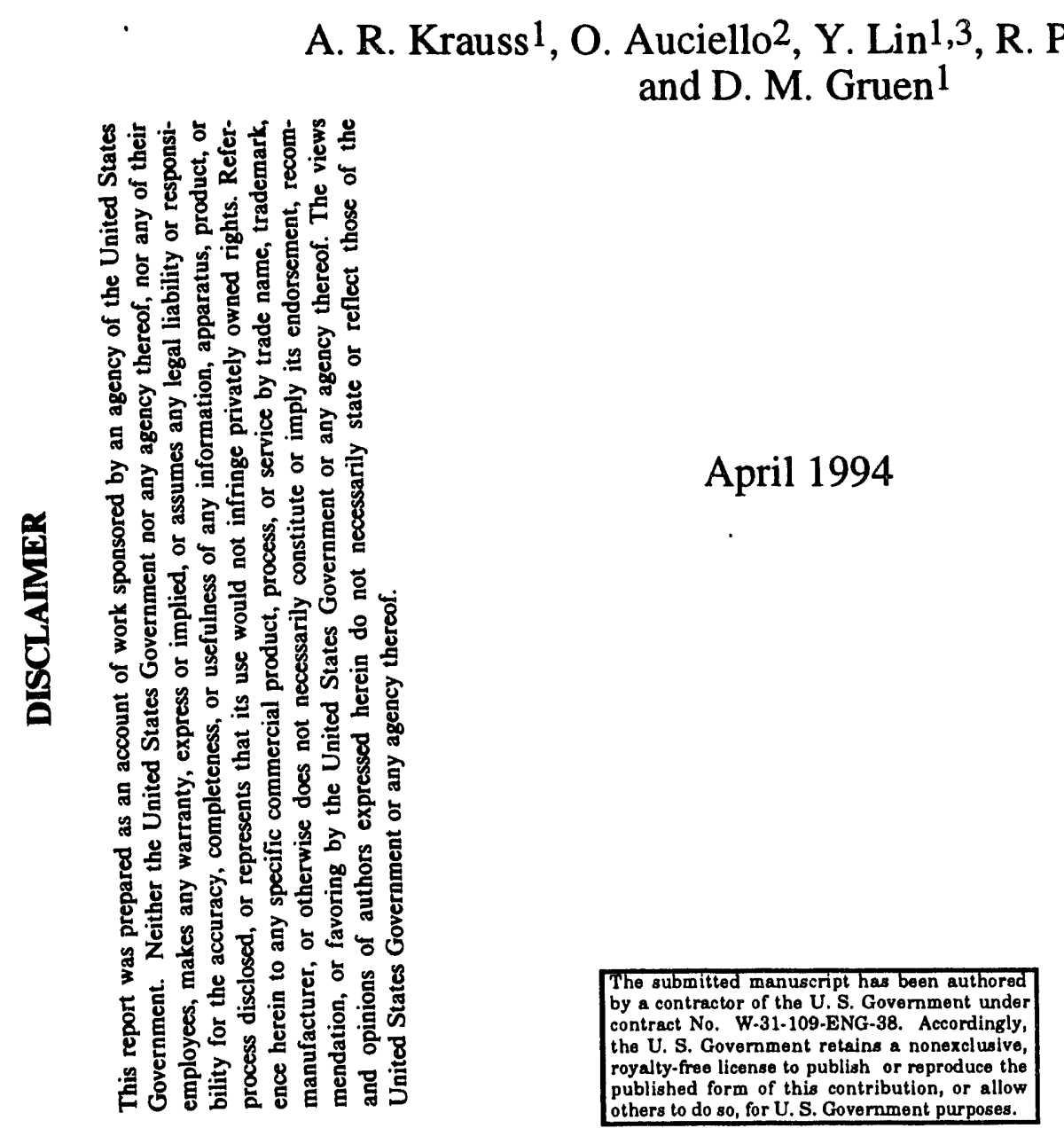

TMaterials Science and Chemistry Divisions, Argonne National Laboratory, Argonne, Illinois $2 \mathrm{MCNC}$, Electronics Technology Division, Research Triangle Park, North Carolina

${ }^{3}$ Northwestern University, Department of Materials Science, Evanston, Illinois

*Work supported by the U.S. Department of Energy, BES-Materials Sciences, under Contract W-31-109-ENG-38, and the Advanced Research Projects Agency under Grant N00014-93-1-0591. 
Sub mitted to Proc. 6th Intern. Symp. on Integrated Ferroelectrics, University of Colorado Press (1994)

\begin{abstract}
TIME-OF-FLIGHT PULSED ION BEAM SURFACE ANALYSIS AS A MEANS OF IN SITU, REAL-TIME CHARACTERIZATION OF THE GROWTH OF FERRO-ELECTRIC AND CONDUCTIVE OXIDE HETEROSTRUCTURES *
\end{abstract}

\author{
A.R. KRAUSS, ${ }^{1}$ O. AUCIELLO, ${ }^{2}$ Y. LIN, 1,3 R. P. H. CHANG, ${ }^{3}$ and \\ D.M. GRUEN 1 \\ (1) Argonne National Laboratory, Materials Science and Chemistry Divisions, \\ Argonne, IL 60439 (2) MCNC, Electronics Technology Division, Research Triangle \\ Park, NC 27709 (3) Northwestern University, Dept. of Materials Science, \\ Evanston, IL 60208
}

\begin{abstract}
Pulsed beam Time-of-Flight Ion Scattering and Recoil Spectroscopy (TOF-ISARS) surface analysis methods have been developed which permit realtime, in situ characterization of the growth layer of multi-component oxide thin films. Results are presented from a study of the deposition of $\mathrm{Pb}, \mathrm{Zr}, \mathrm{Ti}$ and $\mathrm{Ru}$ using a sequential layer-by-layer deposition method under ambient oxygen pressure conditions appropriate to the growth of PZT films, revealing layer-by-layer as well as 2D and 3D island growth processes during deposition. Thermodynamic stability conditions result in modification of the layered structure during deposition, in some cases altering the layer ordering of the growth region. Calculations using the Miedema model for surface segregation are in accord with experimental results that reveal an exchange between deposited $\mathrm{Zr}$ and $\mathrm{Ti}$ atoms and an underlying $\mathrm{Pb}$ layer. In addition, the room temperature studies revealed that $\mathrm{Pb}$ grows layer-by-layer, nucleating as 2D islands, while $\mathrm{Zr}$ tends to form three-dimensional islands. At room temperature, the $\mathrm{Zr}$ surface concentration is strongly enhanced by the presence of oxygen, but at high temperatures, surface $\mathrm{Pb}$ is found to be stabilized by the presence of an oxygen ambient, illustrating the importance of real-time, in situ analysis of the growth layer as opposed to more conventional surface analytical methods which require interruption of the deposition process in order to characterize the film surface.
\end{abstract}

* Work supported by the U. S. Department of Energy, BES-Materials Sciences, under contract W-31-109-ENG and the Advanced Research Projects Agency under grant N00014-93-1-0591

\title{
INTRODUCTION
}

The growth of ferroelectric thin films and integration with metal and metal-oxide conductive layers is currently being investigated for fabrication of electronic memory devices. The high dielectric permittivities of ferroelectric materials can be advantageously used in dynamic random access memories (DRAM), ${ }^{1}$ and the large values of switchable 
spontaneous polarization are suitable for non-volatile ferroelectric random access memories (FRAM). ${ }^{2-7}$

Promising ferroelectric materials for application in memories are $\mathrm{Pb}\left(\mathrm{Zr}_{\mathbf{x}} \mathrm{Ti}_{1-\mathrm{x}}\right) \mathrm{O}_{3}$ (PZT) ${ }^{5-7}$ and a proprietary material named Y1.8 Although not much has been published about the compositional and microstructural characteristics of $Y 1$, a substantial amount of information exists in the literature about PZT. ${ }^{5-7}$ Ferroelectric capacitors with high remanant polarization and low coercive fields have been made with both materials using Pt electrodes. However, device applications require that these properties remain stable for $10^{13}-10^{14}$ switching cycles, and the Pt-PZT-Pt capacitors exhibit polarization fatigue starting at about $10^{6}$ cycles. The fatigue problem for PZT appears to be largely solved, at least up to $10^{11}-10^{12}$ polarization switching cycles (the maximum number of cycles for which these capacitors have been tested $9-15$ ) by using conducting oxide electrode materials such as $\mathrm{RuO}_{2}{ }^{9-11}$ and $\mathrm{La}_{0.5} \mathrm{Sr}_{0.5} \mathrm{CoO}_{3}$ (LSCO) ${ }^{12-15}$. In general, it has been found that the electrode material, and composition and microstructure of the PZT / electrode interface have a strong influence on the electrical characteristics of the capacitor.

It has also been found $11,16,17$ that the growth of the PZT layer itself needs to be controlled to avoid the formation of secondary phases such as pyrochlore or zirconates, which contribute to the degradation of the electrical properties of PZT-based capacitors. It has been demonstrated that secondary phases can be practically eliminated from the PZT layer by growing a template $\mathrm{PbTiO}_{3}$ (PT) layer on the bottom electrode prior to starting the growth of the PZT film $11,16,17$. It is conjectured that the PT layer provides preferential nucleation of the PZT phase and therefore suppresses the Zr-rich phases which nucleate during growth directly on the electrode material ${ }^{11}$.

The progress in producing PZT-based capacitors with controlled composition, microstructure, and electrical properties has been largely based on semiempirical considerations including thermodynamic and kinetic arguments. Direct studies of film nucleation, growth, and interface phenomena are missing from the above-described work because of constraints on the vacuum requirements and geometry of conventional surface analytical instrumentation which make it extremely difficult to perform real-time surface analysis under the conditions necessary for the growth of materials such as PT and PZT. Traditional surface analytic methods require that deposition be terminated, the active gas ambient removed, and the sample transferred to another chamber at much better vacuum than the deposition chamber. In the course of the sample transfer, practical considerations often dictate a change in substrate temperature, typically from the elevated temperature required for the formation of the desired phase to room temperature. The change in 
ambient gas and substrate temperature typically result in a change, often irreversible, in the surface composition and structure such that the surface which is analyzed no longer represents the thin film growth layer. This issue is particularly pressing for materials such as the perovskites since they are typically subject to surface reconstruction, bond enthalpy and oxygen-induced segregation, and kinetic stability phenomena which result in the near-instantaneous modification of the surface composition and structure when the temperature, ambient gas composition or deposition rate are changed.

It has been demonstrated ${ }^{18}$ that by utilizing differential pumping methods to limit the extent of the ambient gas region surrounding the substrate, it is possible to use pulsed ion beam techniques to perform surface analysis at pressures up to 1 Torr. We have been developing an integrated thin film deposition and surface analysis system directed at studying thin film growth dynamics using in situ, real-time ion beam surface characterization techniques.

The automated ion beam sputter deposition system ${ }^{19}$ and the TOF-ISARS 20,21 system have been described in detail elsewhere 20 . We report here results for the in situ, real-time characterization of growing $\mathrm{Pb} / \mathrm{Zr} / \mathrm{Ti}$ layered hetrostructures, with emphasis on understanding the nucleation and initial growth on the bottom electrodes of heterostructure PZT capacitors.

\section{EXPERIMENTAL TECHNIOUE}

A diagram of the integrated IBSD/TOF-ISARS system is shown in Fig. 1. Briefly, the system consists of an UHV surface analysis chamber containing TOF-Ion Scattering (ISS), Direct Recoil (DRS) and Auger electron spectrometers, coupled to a multitarget Ion Beam Sputter Deposition (IBSD) system through a $6 \mathrm{~mm}$ differential pumping aperture. A capillaritron ${ }^{22,23}$ ion gun, producing $\sim 1 \mathrm{~mA}$ of ion beam current at $3-5 \mathrm{keV}$ is used to sputter the target material, depositing through the aperture onto the substrate located on the axis of the analysis chamber. The base pressure of the analysis chamber is in the mid $10^{-10}$ Torr range when pumped by the built-in $200 / \mathrm{sec}$ ion pump, and $\sim 5 \times 10^{-}$ 8 Torr when pumped by a $250 \mathrm{l} / \mathrm{sec}$ turbo pump connected to the load lock chamber. The analysis chamber pressure resulting from gas flowing through the ion gun and into the analysis chamber is typically $\sim 1 \times 10^{-4}$ Torr, requiring the use of the turbo pump. Oxygen can be introduced into the chamber through a leak valve for in situ, real-time characterization of the adsorption of oxygen and growth of ferroelectric and other oxide layers. 
A. R. Krauss, O. Auciello, Y. Lin, R. P. H. Chang and D. M. Gruen

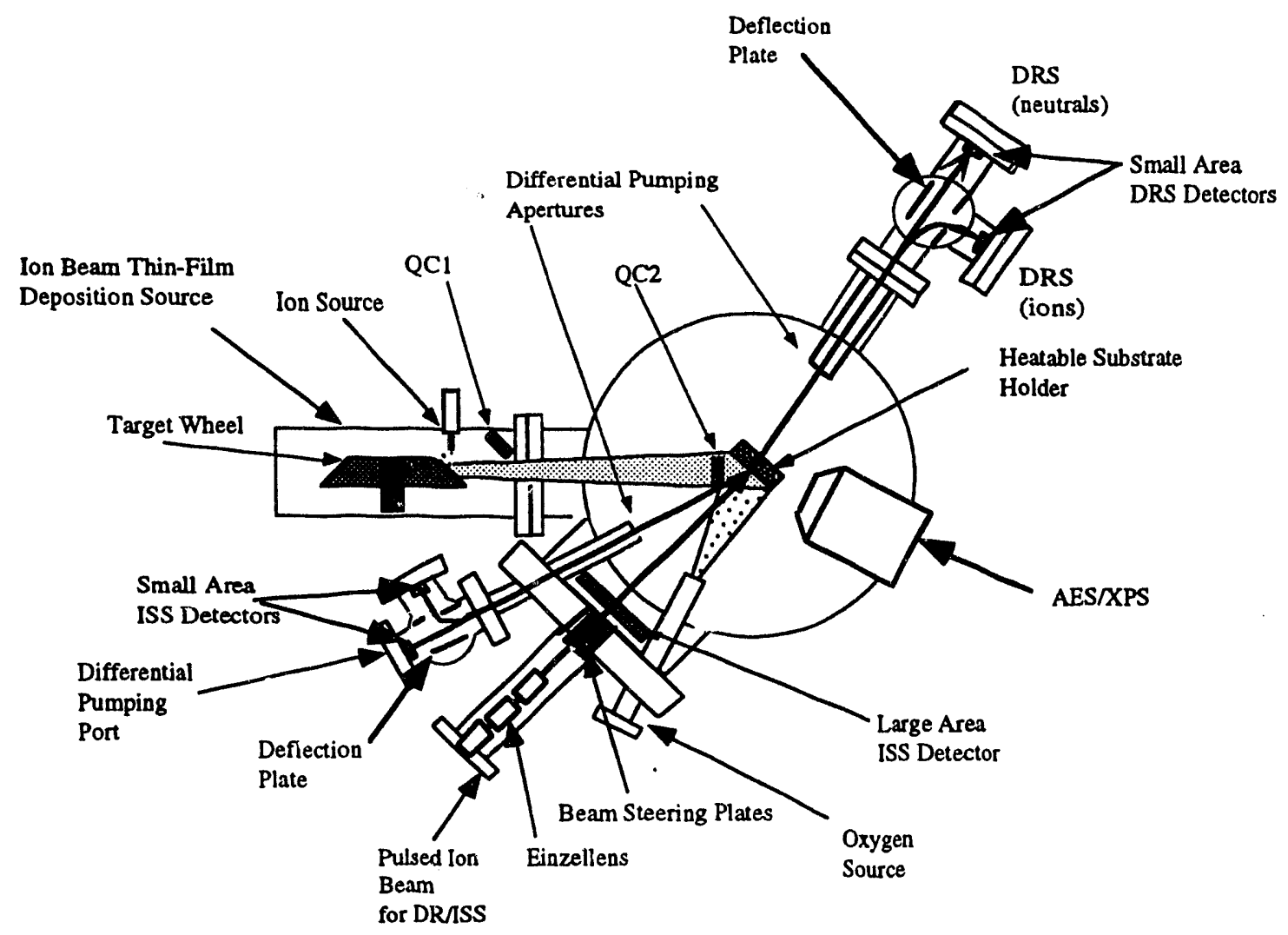

FIGURE 1 Schematic of the integrated thin film deposition and ion beam analysis chamber

Analysis is accomplished by means of a highly collimated inert gas ion beam (typically $10 \mathrm{keV}$ ) produced by an Atomika relefocus ion source, and chopped into pulses 10-500 ns long by two sets of electrostatic deflection plates and four selectable apertures (covering a range $0.125-4 \mathrm{~mm}$ diameter in six steps). The analysis beam strikes the layer growing on the substrate, located on the axis of the analysis chamber, and is scattered at an angle of $165^{\circ}$ through a fixed aperture into a differentially pumped channel electron multiplier detector (see Fig. 1). The scattered ions have different times of flight to the detector depending of the mass of the atoms from which they are scattered. The time of flight in the ISS or DRS spectra identify the species on the surface under analysis. A second differentially pumped detector is positioned in the forward direction to detect direct recoil-ejected surface atoms when using the system in the direct recoil spectrometry mode. The detectors are differentially pumped by $60 \mathrm{~V} / \mathrm{sec}$ turbo pumps, and view the sample through 1-1.5 mm apertures located at the end of a $1.3 \mathrm{~cm}$ diameter tube positioned $5-15 \mathrm{~cm}$ from the sample. A tungsten filament positioned in front of the detector casts a spot of light through the differential pumping aperture onto the area of the sample which is viewed by the detector. Although the ion beam must be carefully positioned on the substrate to obtain maximum signal intensity, the alignment is performed entirely by means of electrostatic deflection, and none of the apertures require 


\section{TIME-OF-FLIGHT PULSED ION BEAM SURFACE ANALYSIS AS A MEANS ...}

mechanical adjustment. Depending on the combined distance from the ion beam exit aperture to the sample and from the sample to the detector aperture, it is possible to perform surface analysis at ambient pressures ranging from 10 to $\sim 50$ mTorr without interfering with the deposition process.

\section{RESULTS AND DISCUSSION}

PZT films with high remanant polarization and low coercive fields have been produced 11 by depositing thin layers of $\mathrm{Zr}$, $\mathrm{Ti}$ and $\mathrm{Pb}$ onto an $\mathrm{MgO}$ substrate in layer thicknesses of $2.5,6.5$ and $15 \AA$ (corresponding to layers $\sim 0.85,2.4$ and 4.7 monolayers (ML) thick respectively) at a temperature of $550^{\circ} \mathrm{C}$ in an oxygen atmosphere of $5 \times 10^{-4}$ Torr. The stoichiometry is controlled by the layer thicknesses, and the deposition temperature is high enough to promote mixing at the deposition rates of 0.25 $\AA / \mathrm{sec}$ for $\mathrm{Zr}, 0.16 \AA / \mathrm{sec}$ for $\mathrm{Ti}$, and $1.5 \AA / \mathrm{sec}$ for $\mathrm{Pb}$. This combination of materials however, is subject to large segregation energies, resulting in unmixing, preferential oxidation and preferential evaporation. The Gibbsian segregation energy 24 associated with minimization of the surface free energy by exchanging atoms between the first and second atomic layers is calculated by a model 25 using the Miedema theory of alloy formation ${ }^{26}$. It is found that $\mathrm{Pb}$ preferentially segregates relative to $\mathrm{Ti}$ (by $1.11 \mathrm{eV}$ ), and to $\mathrm{Zr}$ (by $0.83 \mathrm{eV}$ ). For $\mathrm{Zr}$ and $\mathrm{Ti}$, there is a very small preferential $\mathrm{Zr}$ segregation energy $(0.02 \mathrm{eV})$. In the presence of a partial pressure of oxygen however, surface oxidation modifies the Gibbsian segregation energy, resulting in a tendency to promote the segregation of the metal with the highest heat of oxide formation. Since $\mathrm{ZrO}_{2}$ and $\mathrm{TiO}_{2}$ have high heats of formation (262 gram cal/mol and $228 \mathrm{gram} \mathrm{cal} / \mathrm{mol}$ respectively) relative to $\mathrm{PbO}$ (53 gram cal $/ \mathrm{mol}$ ), the effect of ambient oxygen is to strongly modify the segregation behavior predicted on the basis of Miedema's parameters for alloy formation in the presence of a vacuum ambient. The strong $\mathrm{Pb}$ segregation will therefore be suppressed in oxygen, although the relative surface concentration of $\mathrm{Zr}$ vs $\mathrm{Ti}$ is harder to predict.

In order to characterize phenomena occurring during nucleation and initial growth of the PZT phase, we have used TOF-ISS to monitor the surface composition during and after deposition of $\mathrm{Pb}, \mathrm{Zr}$ and $\mathrm{Ti}$ layers from elemental targets. Fig. 2 shows an ISS spectrum taken immediately after deposition of $1.7 \AA$ of $\mathrm{Zr}$ onto a surface consisting of $\sim 2 \AA$ of $\mathrm{Pb}$ on an $\mathrm{MgO}(100)$ substrate at room temperature in a background of $1 \times 10^{-4}$ Torr of $\mathrm{Kr}$ resulting from $\mathrm{Kr}$ gas diffusing from the sputtering chamber into the ISS chamber. $\mathrm{Pb}$ represents the largest peak even though only a small amount of $\mathrm{Pb}$ was deposited, and $\sim 0.7 \mathrm{ML}$ of $\mathrm{Zr}$ has been deposited on top of the $\mathrm{Pb}$ layer. Additional lines are present, corresponding to $\mathrm{Cu}$ and $\mathrm{Ag}$ impurities. In addition, there is a peak at 2.6 
$\mu \mathrm{sec}$, corresponding to a prompt signal resulting from $\mathrm{x}$-ray production when the primary ion beam strikes the sample 27 . The presence of this peak is correlated to the presence of adsorbed oxygen at the surface, and the peak is generally absent for clean metal surfaces. The width of the prompt peak is determined by the time resolution of the data acquisition system and the width of the primary ion beam pulse. The $\mathrm{Pb}, \mathrm{Zr}$ and $\mathrm{Cu}$ peaks are comparable in width to the prompt peak, indicating that there is little or no multiple scattering of the primary ion 20 .

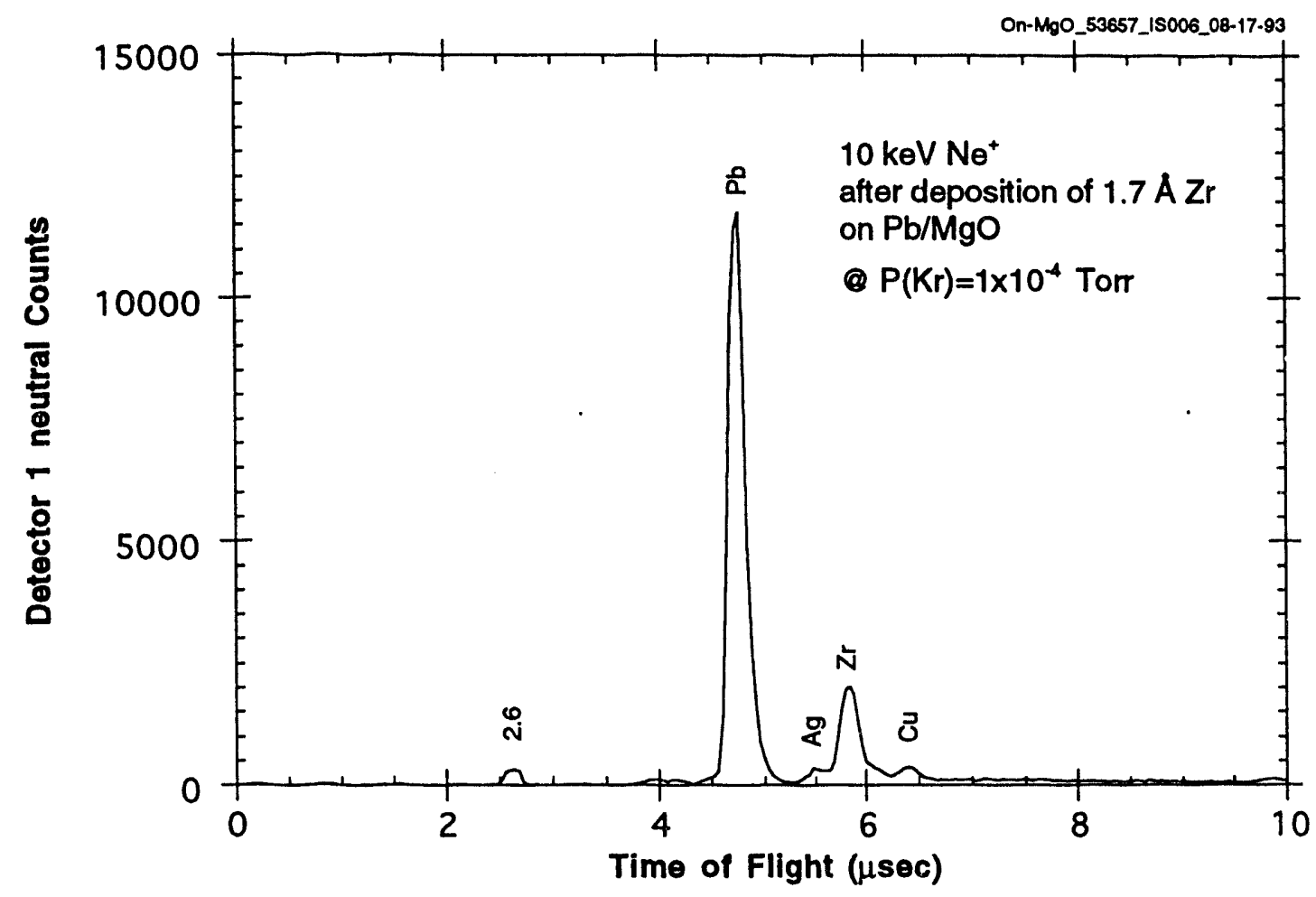

FIGURE 2. ISS data taken immediately after deposition of $1.7 \AA \mathrm{Zr}$ onto a very thin

$(\sim 2 \AA)$ layer of $\mathrm{Pb}$ on an $\mathrm{MgO}(100)$ substrate.

A series of spectra for the above sample as a function of primary ion angle of incidence exhibit a splitting of the $\mathrm{Pb}$ peak as shown in Fig. 3. The nominal position of the $\mathrm{Pb}$ peak for a $10 \mathrm{keV} \mathrm{Ne}+$ ion beam is $4.88 \mu \mathrm{s}$. For near-normal ion beam incidence there are instead two sharp peaks at 4.32 and $4.59 \mu \mathrm{s}$. As the angle of incidence is increased, the relative intensity of the two peaks changes, with the longer time of flight peak dominating at angles of incidence greater than 9 degrees from the surface normal. As shown in Fig. 4, this situation occurs when there are two adjacent $\mathrm{Pb}$ atoms in the uppermost layer, corresponding to film nucleation via formation of two-dimensional islands in a layer-by-layer growth mode. This effect has been observed in other systems and carefully documented. 

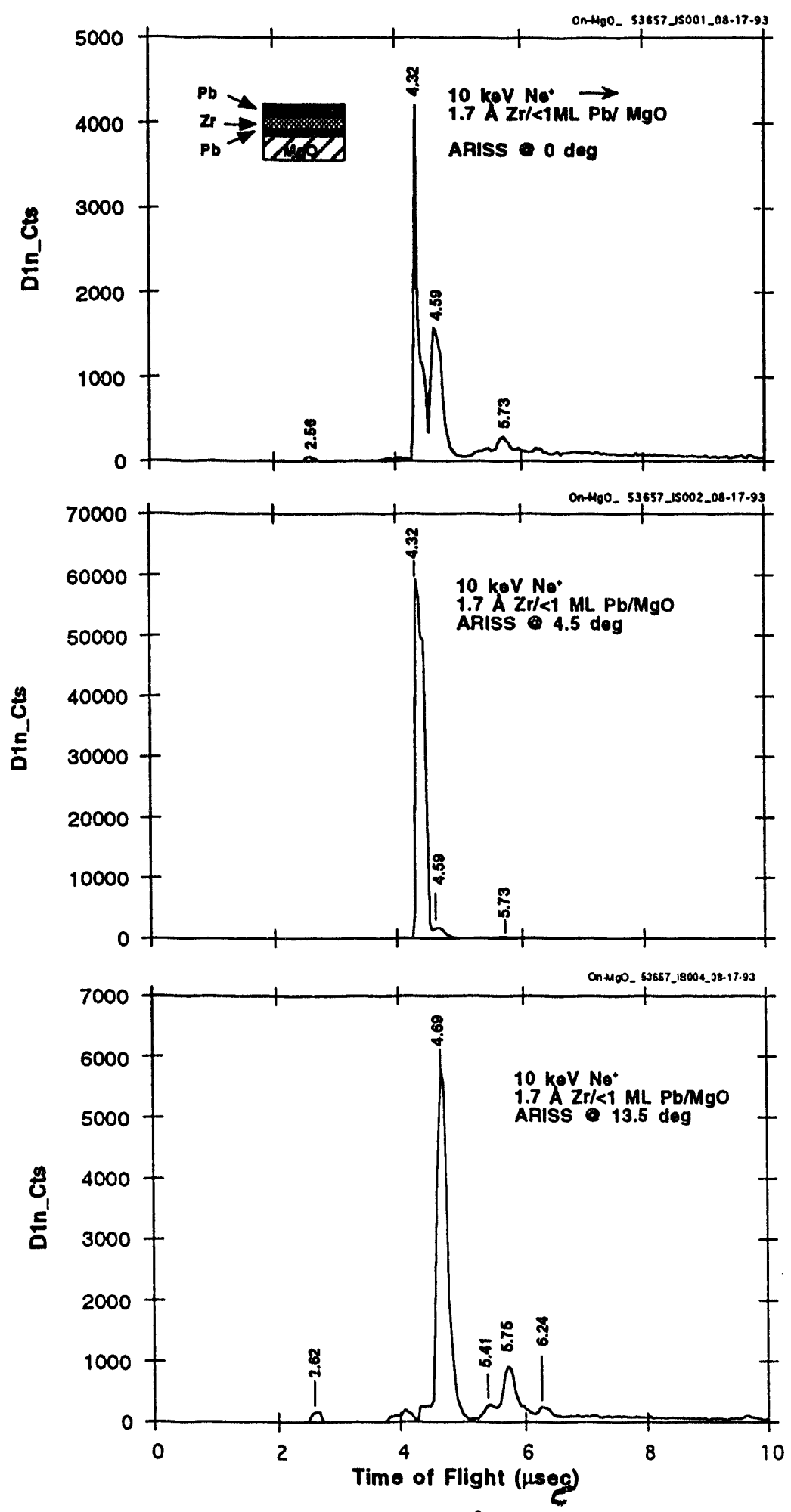

FIGURE 3. ISS data after deposition of $1.7 \AA \mathrm{Zr}$ onto $\mathrm{Pb} / \mathrm{MgO}$ for 3 different angles of primary ion incidence. 
A. R. Krauss, O. Auciello, Y. Lin, R. P. H. Chang and D. M. Gruen

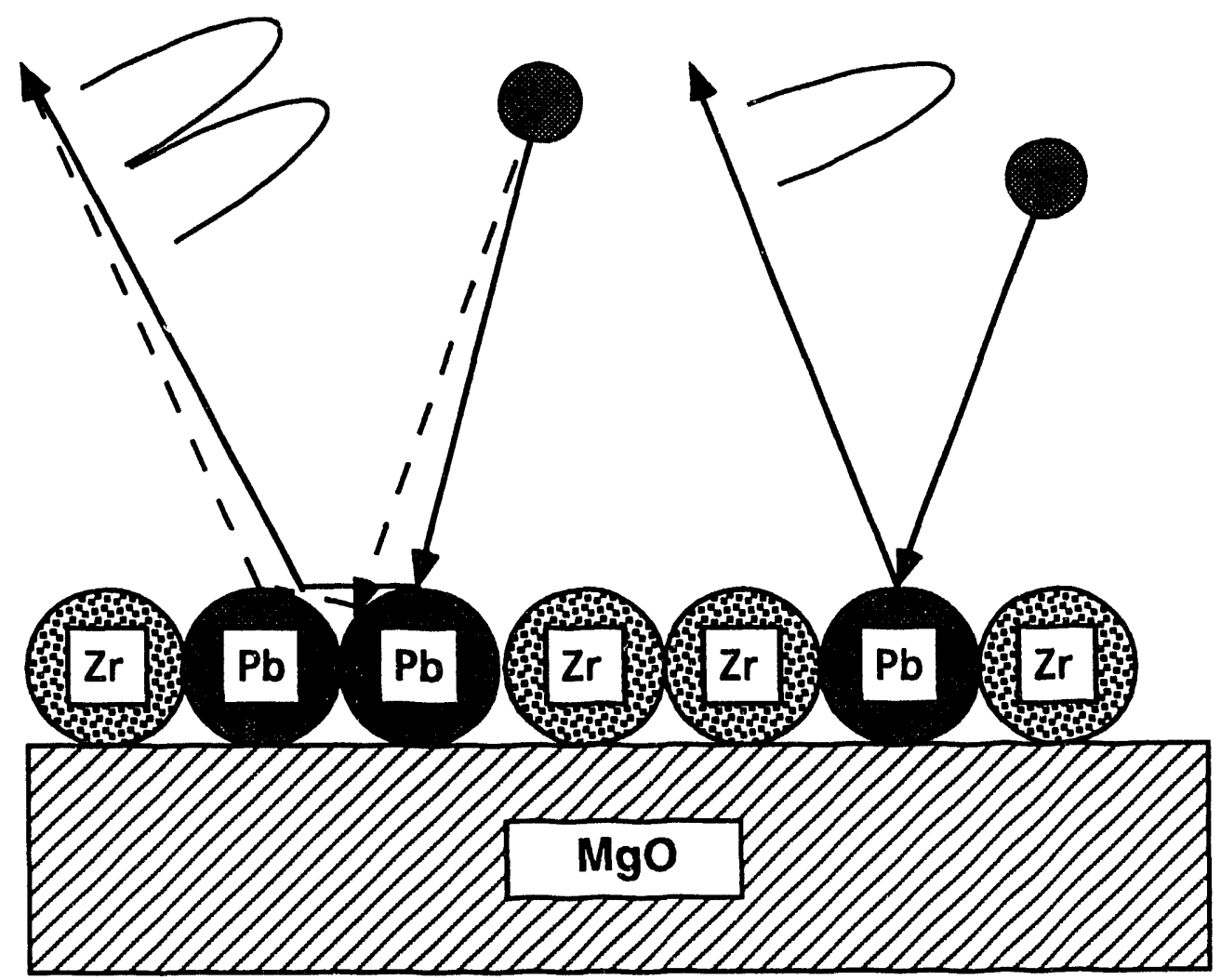

FIGURE 4. Model of scattering events leading to the split $\mathrm{Pb}$ peak observed for certain angles of primary beam incidence.

Figure 5 shows ISS data taken with the ion beam incident at an angle of 43 degrees to the substrate normal during $\mathrm{Pb}$ deposition of $\sim 10.1 \AA(2.8 \mathrm{ML})$ on the surface corresponding to the model shown in Fig. 4. The pressure in the chamber is $1 \times 10^{-4}$ Torr, consisting primarily of the $\mathrm{Kr}$ gas load associated with the $\mathrm{Kr}^{+}$ion beam used to sputter the $\mathrm{Pb}$ target. For 43 degree primary ion incidence, a broad background, corresponding to multiple scattering from a low mass (presumably hydrocarbon) layer appears, and the $\mathrm{Zr}$ peak disappears into the background while the $\mathrm{Pb}$ peak retains its narrowness and symmetric shape. A narrow, symmetric peak is indicative of a lack of multiple scattering, corresponding either to incidence along a crystalline axis or a very thin layer, not exceeding 1-2 monolayers in thickness. As the deposition continues, the $\mathrm{Pb}$ peak intensity increases, although the peak shape remains constant. This result is unlike that obtained for $\mathrm{Pb}$ growth on a $\mathrm{Ru} / \mathrm{Pb}$ layered structure on stainless steel monitored by normal incidence ISS ${ }^{28}$. In that work, it was found that there were distinct steps occurring at thicknesses of 1 and $2 \mathrm{ML}$ for which the rate of increase of the $\mathrm{Pb}$ signal either decreased abruptly or ceased altogether. 


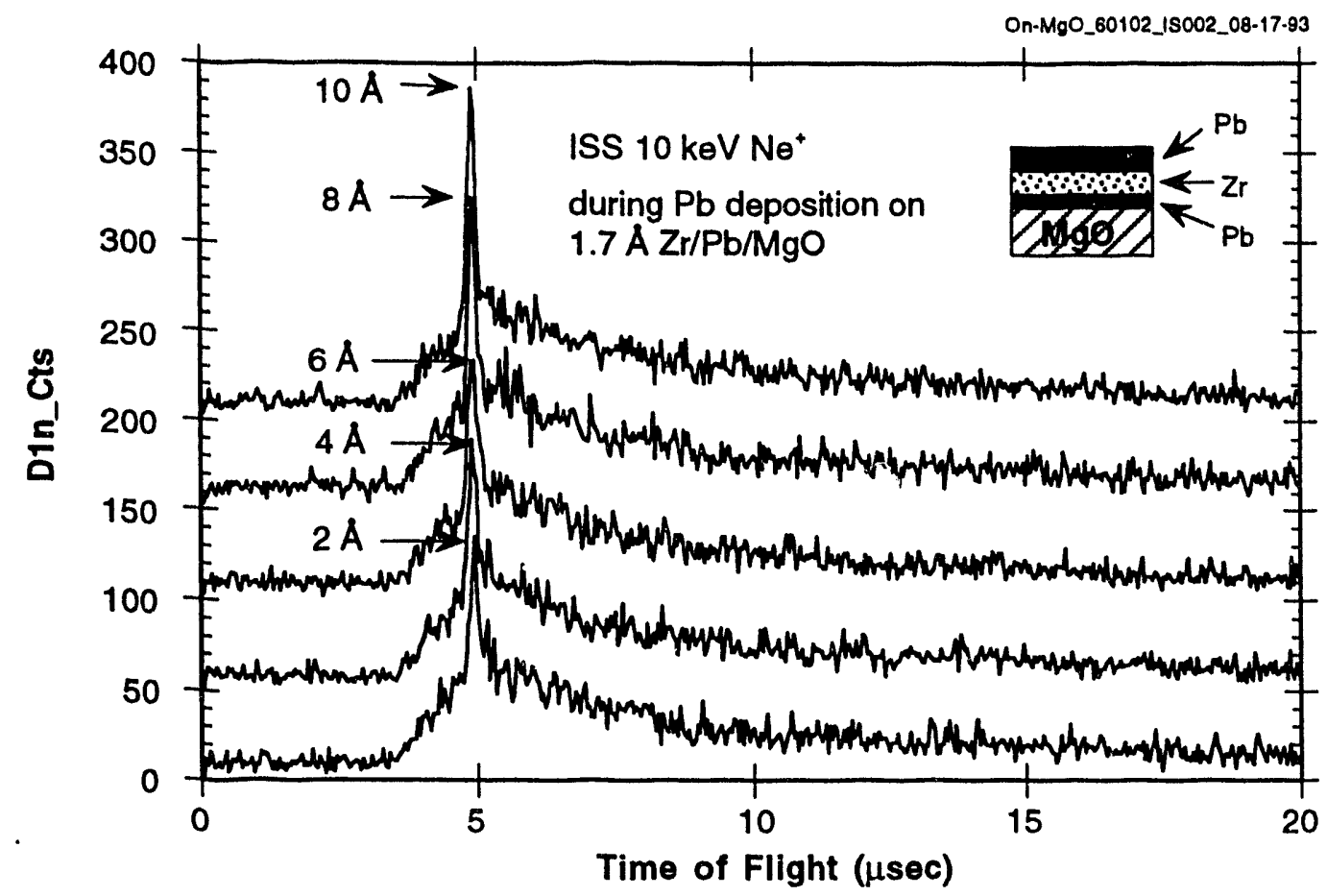

FIGURE 5. ISS data acquired during $\mathrm{Pb}$ deposition on $1.7 \AA$ of $\mathrm{Zr}$ on an $\mathrm{MgO}(100)$ substrate.

Fig. 6 shows four ISS spectra during $\mathrm{Pb}$ deposition onto the sample shown in Fig. 5 (a), and 3,14 and 22 minutes after deposition ceased (b-d).The $\mathrm{Zr}$ peak started to increase almost immediately, appearing as an asymmetric peak corresponding to multiple scattering, while $\mathrm{Pb}$ maintained its narrow width and symmetric shape. The ambient gas consists primarily of $1 \times 10^{-4}$ Torr of $\mathrm{Kr}$, resulting from admission of the sputtering gas. However, previous experiments in this chamber ${ }^{29}$ using DRS have shown the appearance of hydrogen, oxygen and carbon impurities along with both inert gas and oxygen admission. It appears therefore that chemisorption-induced segregation results in the formation of 3-dimensional $\mathrm{Zr}$ islands at the surface. Further experiments are requied to quantify this behavior.

Fig. 7 shows spectra taken during deposition of Ti onto the surface corresponding to Fig. 6d. Although $27 \AA$ of Ti was deposited, no Ti peak appeared in the spectrum. The principal effect of deposition of as little as $0.4 \AA$ of Ti was the suppression of the $\mathrm{Zr}$ signal and re-emergence of $\mathrm{Pb}$ as the dominant peak. As Ti deposition continued, the $\mathrm{Zr}$ signal slowly reappeared. Ti deposition was terminated after 1 hour without the appearance of any $\mathrm{Ti}$ signal. The beam was then turned off for 11 hours. Upon resumption of data acquisition, the spectrum of Fig. 8 was obtained. $\mathrm{Zr}$ is now the dominant peak, followed by $\mathrm{Ti}$, with a weak $\mathrm{Pb}$ signal. The presence of a strong $\mathrm{t}=0$ peak is indicative of adsorbed oxygen. 


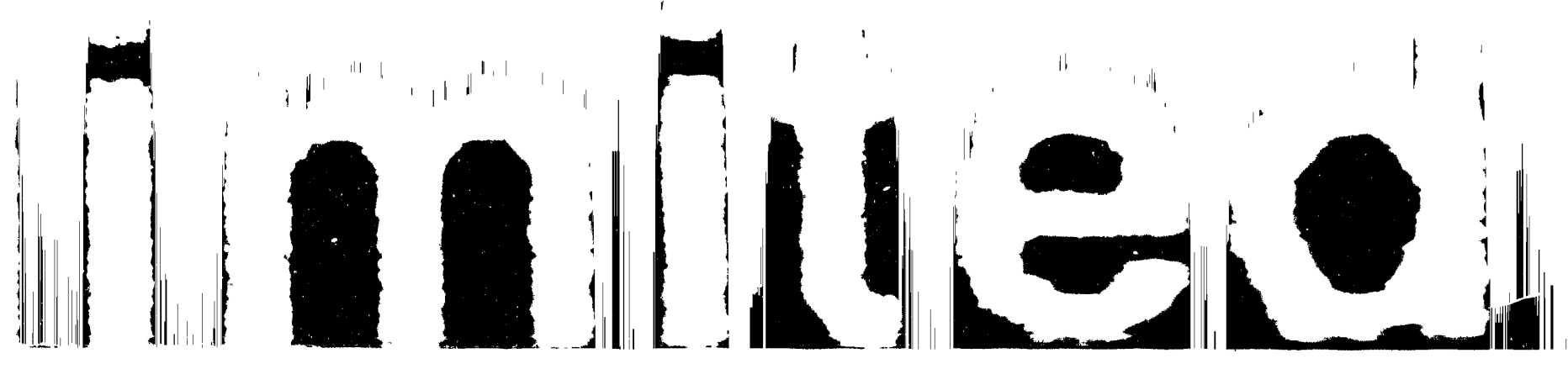

A. R. Krauss, O. Auciello, Y. Lin, R. P. H. Chang and D. M. Gruen

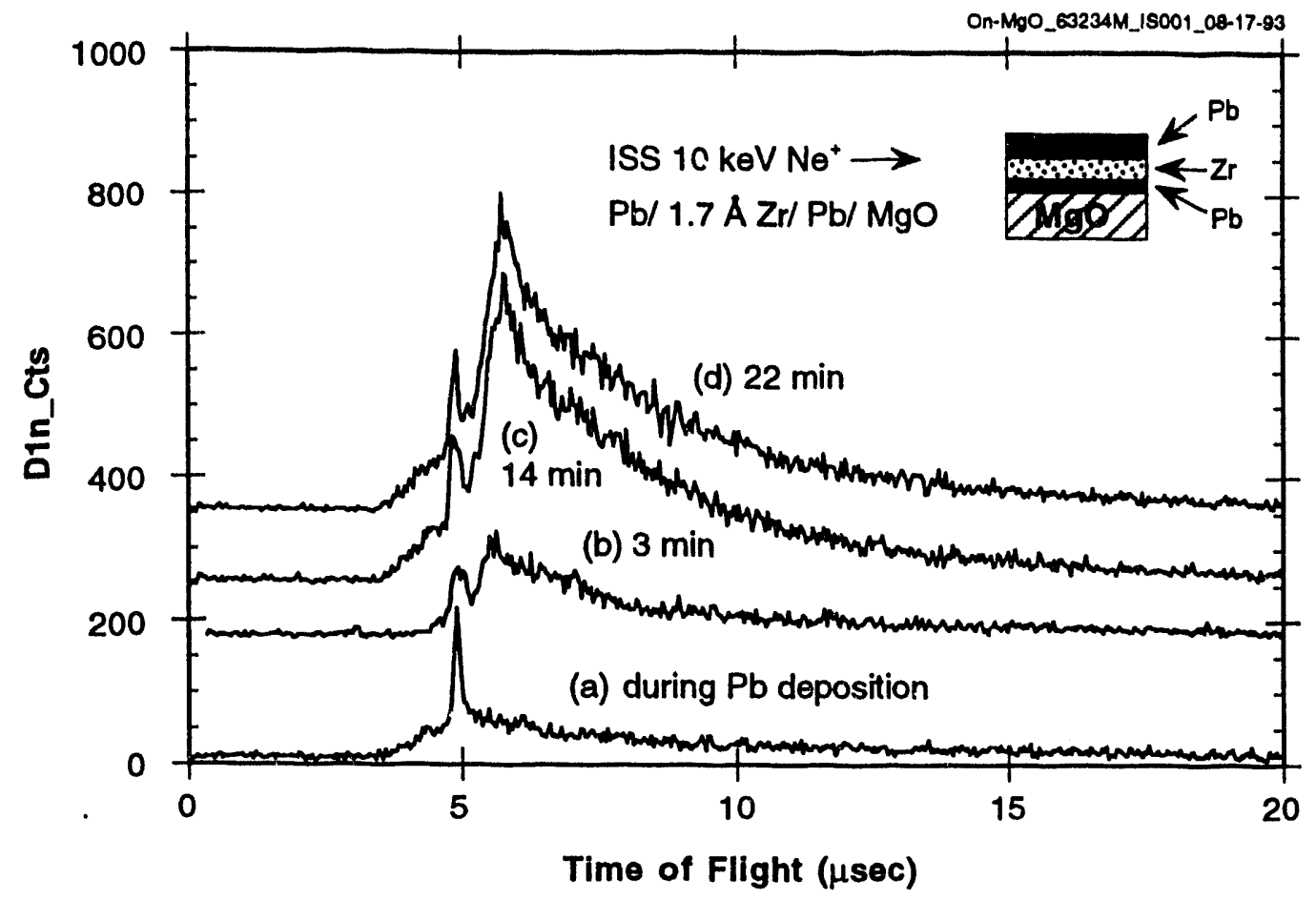

FIGURE 6. ISS data taken during $\mathrm{Pb}$ deposition onto a $\mathrm{Zr} / \mathrm{Pb}$ layered structure on $\mathrm{MgO}(100)$, and at selected intervals after termination of $\mathrm{Pb}$ deposition.

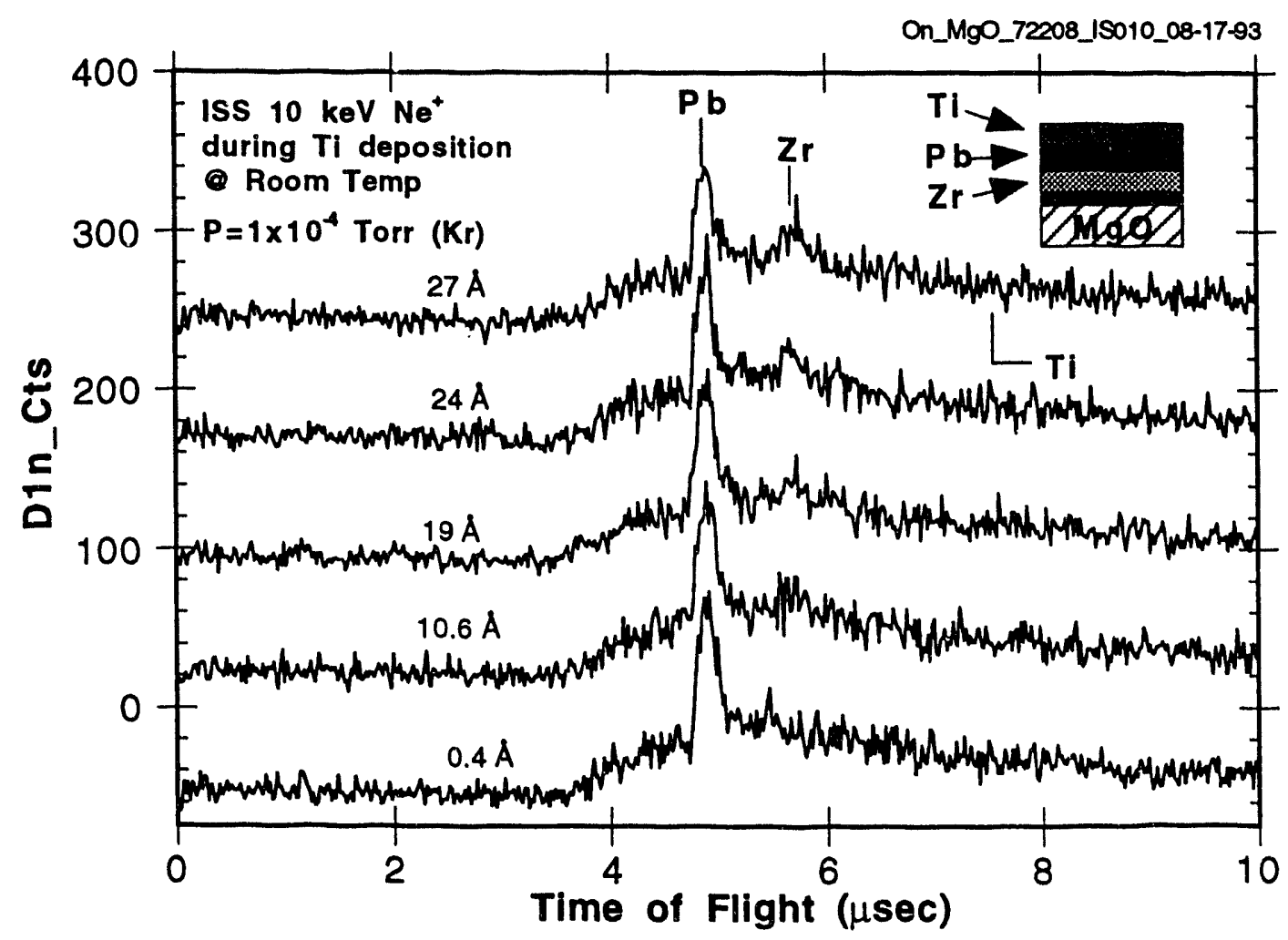

FIGURE 7. ISS data acquired during Ti deposition onto the surface corresponding to figure $6 \mathrm{~d}$. 


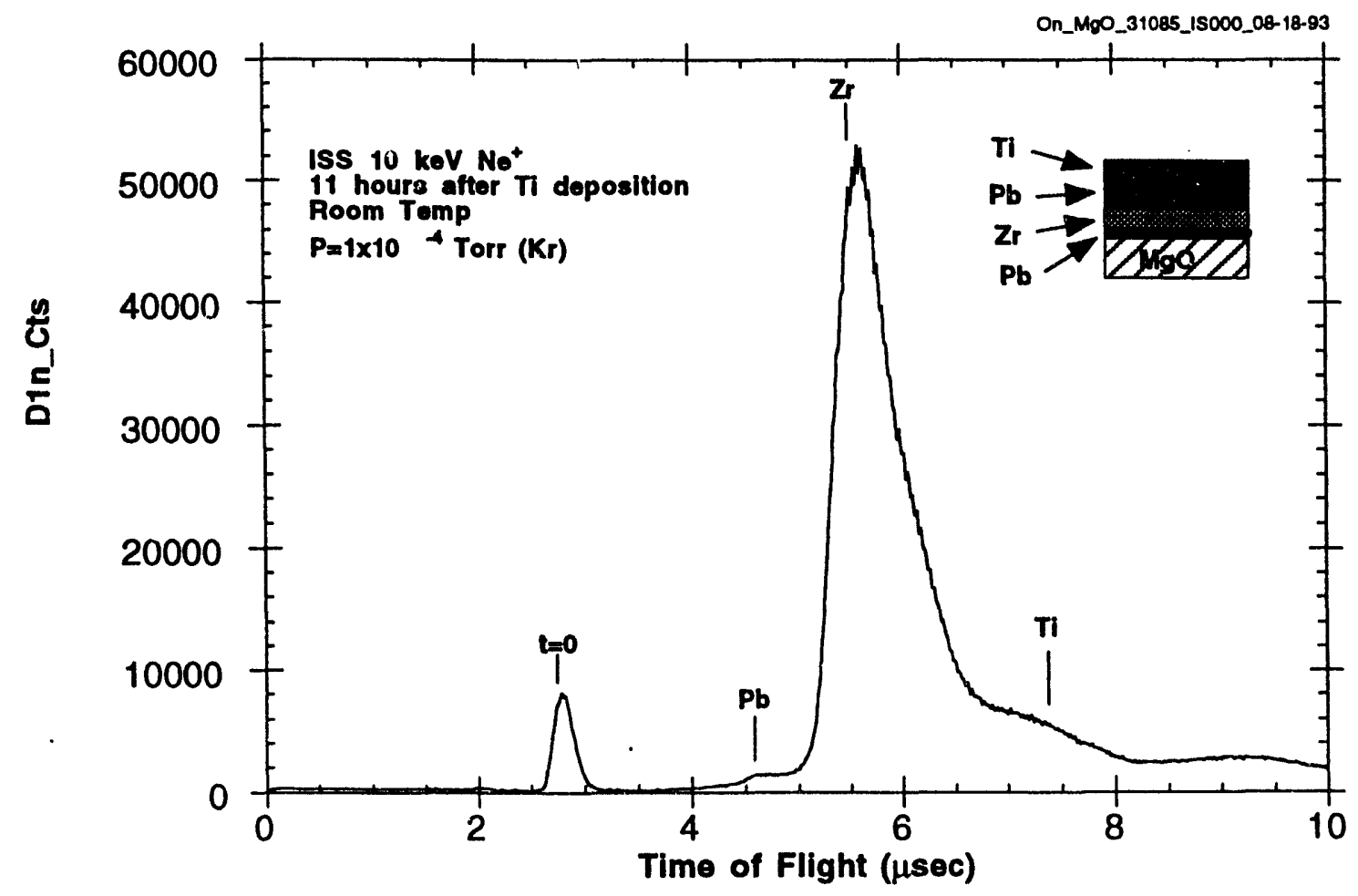

FIGURE 8. ISS data corresponding to final scan of Fig. 7 after 11 hour delay.

A second sample (Fig. 9) consisting of a similar $\mathrm{Pb}, \mathrm{Zr}$ and $\mathrm{Ti}$ layered structure on top of a $1000 \AA$ thick layer of $\mathrm{RuO}_{2}$ on an $\mathrm{MgO}(100)$ substrate yielded similar results, i.e. initial dominance of the $\mathrm{Pb}$ signal with subsequent growth of $\mathrm{Zr}$ as 3-dimensional islands, and little or no Ti signal. In order to simulate the growth conditions for the PZT phase, the sample was annealed to a temperature of $570^{\circ} \mathrm{C}$ in an atmosphere of oxygen at $5 \times 10^{-4} \mathrm{Torr}$ for approximately 1 hour. There still was no evidence of $\mathrm{Ti}, \mathrm{Zr}$ was the dominant peak, with an asymmetric shape corresponding to a thick disordered structure, and the $\mathrm{Pb}$ signal, although reduced somewhat from its room temperature magnitude, was still present as a symmetric, well-defined peak. Upon cessation of the oxygen flow, the $\mathrm{Pb}$ signal disappeared completely within three minutes.

The following model is proposed to explain the experimental results: At room temperature in vacuum, $\mathrm{Pb}$ is the preferred species since a single atomic layer of $\mathrm{Pb}$ reduces the surface free energy. $\mathrm{Zr}$ initially deposits as a coherent layer on top of $\mathrm{Pb}$, but quickly "clumps" into three-dimensional islands. If $\mathrm{Pb}$ is deposited on top of $\mathrm{Zr}$, the $\mathrm{Pb}$ signal will initially dominate, but with time (and exposure to residual gas), the surface becomes $\mathrm{Zr}$-rich. In vacuum, $\mathrm{Zr}$ is expected to segregate with a slight preference over $\mathrm{Ti}$. This preferential $\mathrm{Zr} / \mathrm{Ti}$ segregation is enhanced in the presence of oxygen because of the 
somewhat higher heat of oxide formation for $\mathrm{Zr}$, with the result that although clearly present in the film, Ti does not initially occupy a position in the uppermost atomic layer. However, since $\mathrm{Ti}$ competes with $\mathrm{Zr}$ for the available oxygen, the surface becomes oxygen-depleted and consequently $\mathrm{Pb}$ re-emerges as the dominant surface species. With continued oxygen exposure, $\mathrm{Zr}$ again forms 3-dimensional islands. eventually dominating the surface composition. Once the surface has become oxygen-saturated and the $\mathrm{Zr}$ island structure has stabilized, some Ti appears at the surface, although it remains a minority species. At high temperature, the rapid segregation of $\mathrm{Pb}$ results in a surface which contains a significant proportion of $\mathrm{Pb}$ in the presence of a relatively high background pressure of oxygen. Unlike the room temperature case however, because of the high vapor pressure of $\mathrm{Pb}$, oxygen is now required to stabilize surface $\mathrm{Pb}$, presumably as $\mathrm{PbO}$.

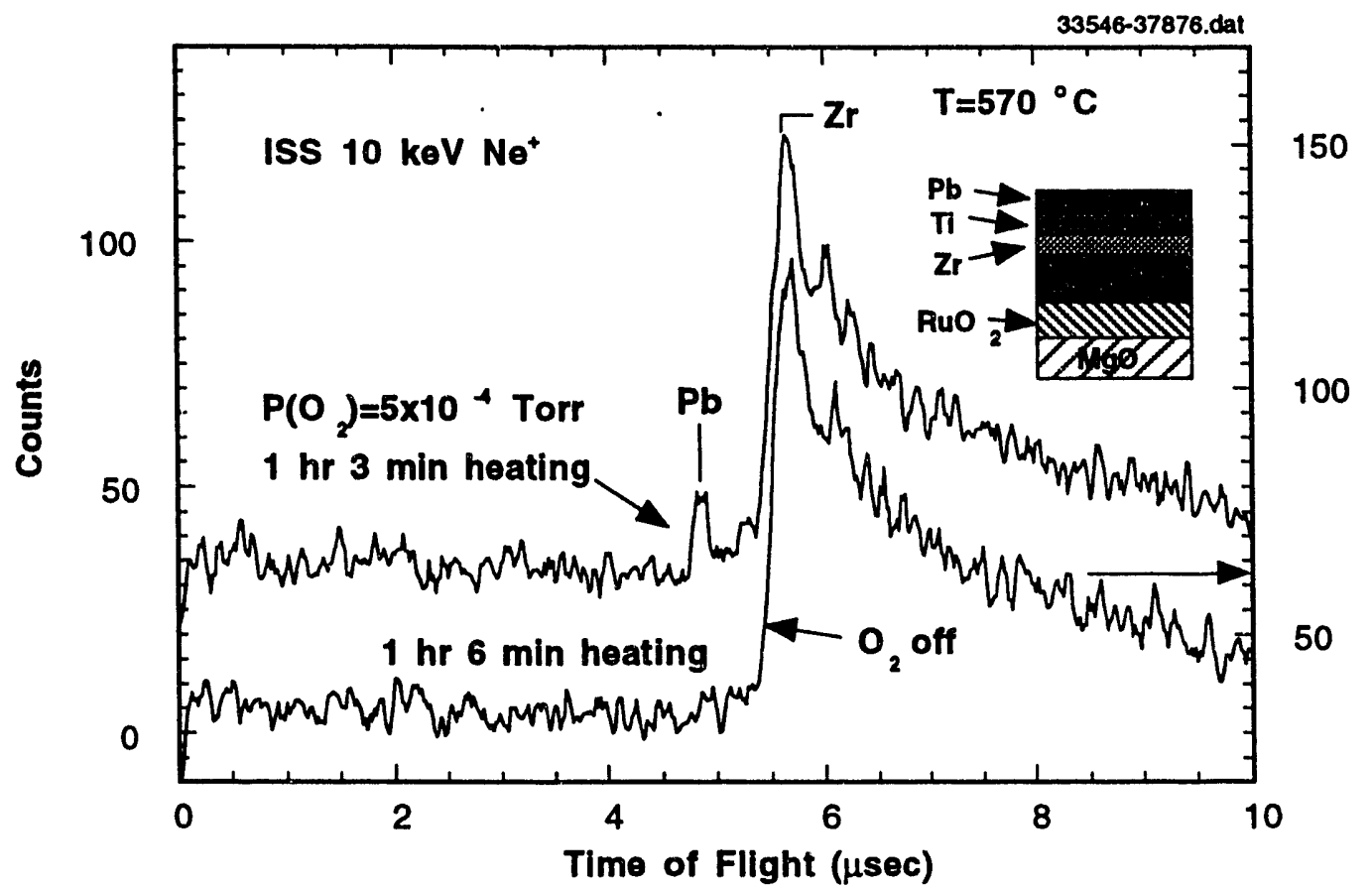

FIGURE 9. ISS data for a $\mathrm{Pb} / \mathrm{Ti} / \mathrm{Zr} / \mathrm{Pb} / \mathrm{Ti}$ structure annealed to $570^{\circ} \mathrm{C}$, with and without an ambient $5 \times 10^{-4}$ Torr oxygen background.

\section{SUMMARY}

The surface composition of an ultrathin layered structure of $\mathrm{Pb}, \mathrm{Zr}$ and $\mathrm{Ti}$ with layer thicknesses representative of those used to produce homogeneous PZT varies significantly as a function of the oxygen ambient pressure. The compositional changes of the growth layer are sufficiently rapid to prevent observation by conventional surface 
analytical methods which require lowering the deposition chamber pressure to the $10^{-7}$ 10-9 Torr range or transferring the sample to an UHV surface analysis chamber, both at room temperature and at the elevated temperature used during growth. The observed room temperature effects of the presence or lack of oxygen at the surface are consistent with the explanation of the fatigue process in PZT capacitors with metal electrodes as the result of oxygen vacancies at the surface of the PZT layer migrating into the bulk, resulting in formation of the pyrochlore phase at the PZT-electrode interface. At room temperature, deprivation of oxygen promotes a uniformly $\mathrm{Pb}$-rich surface, resulting in the possible formation of a pyrochlore phase covering the entire electrode interface of a PZT capacitor, while oxygen presence promotes the formation of localized three-dimensional $\mathrm{Zr}$ islands at the surface, with the possible formation of localized zirconate phases at the electrode interface. The formation of a surface titanate phase is unlikely since Ti never appears to be a majority surface species. However, subsurface Ti does affect the surface concentration, promoting dominance of $\mathrm{Pb}$, presumably by competing with $\mathrm{Zr}$ for the available oxygen with the production of oxygen vacancies at the surface. However, a $\mathrm{PbTiO}_{3}$ buffer layer may function either as a source of oxygen to suppress oxygen vacancy migration, or as a source of $\mathrm{Pb}$ at the $\mathrm{PZT}$-electrode interface which inhibits $\mathrm{Pb}$ segregation from the bulk to the interface. These proposed mechanisms are preliminary and further work is needed to verify them.

\section{REFERENCES}

1. J. Carrano, C. Sudhama, J. Lee, A. Tasch, W.H. Shepherd, and N. Abt, IEEE Trans. Ultrasonics. Ferroelectrics, and Freq. Control, 38, 690 (1991).

2. J.T. Evans and R. Womack, IEEE J. Solid State Circuits. 23, 1171 (1988).

3. J.F. Scott and C.A. Paz de Araujo, Science 246, 1400 (1989).

4. S. Dey and R. Zuleeg, Ferroelectrics, 108, 37 (1990).

5. Proceedings of the 3rd International Symposium on Integrated Ferroelectrics, edited by C.A. Paz de Araujo (University of Colorado Press, Colorado Springs 1991). Also, Proceedings of the 4th International Symposium on Integrated Ferroelectrics edited by C.A. Paz de Araujo (University of Colorado Press, Colorado Springs, 1992).

6. Materials Research Society Symp. Proc. "Ferroelectric Thin Films I (vol. 200, 1990), edited by E.R. Myers and A.I. Kingon, and "Ferroelectric Thin Films II" (vol. 243, 1991), edited by A.I. Kingon, E.R. Myers, and B. Tuttle (Materials Research Society, Pittsburgh, Pennsylvania).

7. Multicomponent and Multilayered Thin Films for Advanced Microtechnologies: Techniques, Fundamentals and Devices, NATO/ASI Book Series E, vol. 234, edited by $O$. Auciello and J. Engemann (Kluwer Academic Publishers, The Netherlands, 1993).

8. T. Mihara, H. Watanabe, C.A. Paz de Araujo, J. Cuchiaro, M. Scott, L.D. McMillan, Proceedings of the 4th International Symposium on Integrated 

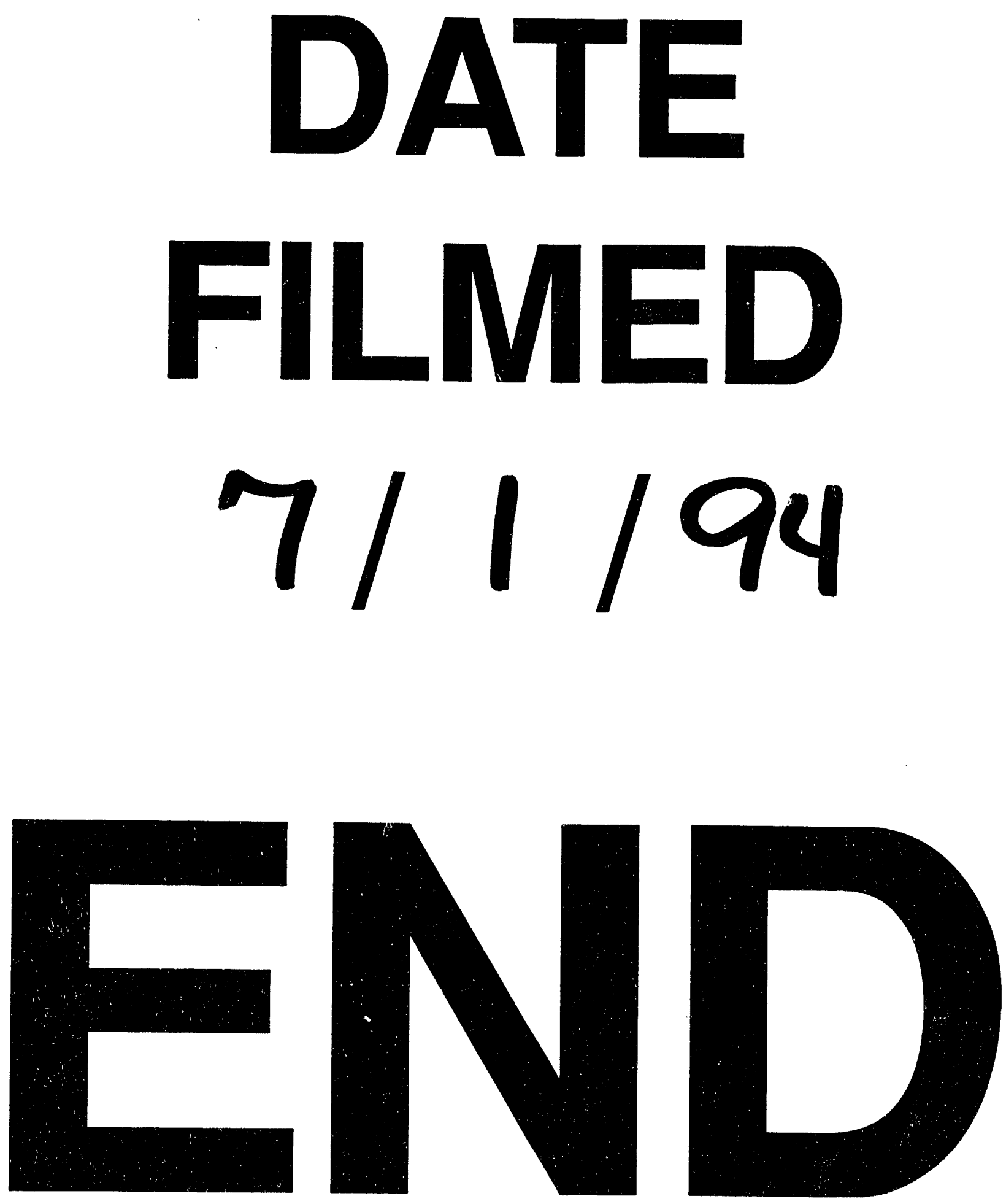


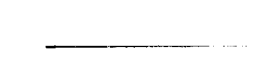

